\title{
(息)
}

Citation:

Kime, NH and Mckenna, J and Griffiths, $\mathrm{C}$ and Rivett, M and Gately, P (2018) A qualitative evaluation of healthy weight services in a local authority in England. Health Education Journal. ISSN 1748-8176 DOI: https://doi.org/10.1177/0017896918786987

Link to Leeds Beckett Repository record:

https://eprints.leedsbeckett.ac.uk/id/eprint/5165/

Document Version:

Article (Accepted Version)

The aim of the Leeds Beckett Repository is to provide open access to our research, as required by funder policies and permitted by publishers and copyright law.

The Leeds Beckett repository holds a wide range of publications, each of which has been checked for copyright and the relevant embargo period has been applied by the Research Services team.

We operate on a standard take-down policy. If you are the author or publisher of an output and you would like it removed from the repository, please contact us and we will investigate on a case-by-case basis.

Each thesis in the repository has been cleared where necessary by the author for third party copyright. If you would like a thesis to be removed from the repository or believe there is an issue with copyright, please contact us on openaccess@leedsbeckett.ac.uk and we will investigate on a case-by-case basis. 


\section{A qualitative evaluation of healthy weight services in a local authority in England}

Nicky Helen Kime ${ }^{a}$, Jim McKenna ${ }^{a}$, Claire Griffiths ${ }^{a}$, Martin Rivett ${ }^{a}$ and Paul Gately ${ }^{b}$

${ }^{a}$ Carnegie School of Sport, Leeds Beckett University, Leeds, UK

${ }^{b}$ More Life, Leeds Beckett University, Leeds, UK

\section{Abstract}

\section{Objective}

The purpose of this study was to evaluate the healthy weight services in one local authority in England, where obesity levels have been above the national average since 2006.

\section{Design}

We conducted process and outcome evaluation using a qualitative methodology. Data were generated in focus group discussions and semi-structured interviews with clients, practitioners, healthcare professionals and volunteers.

\section{Results}

Ninety-one individuals from six services participated in the evaluation. Staff competencies and empowerment outcomes were identified as areas of strength. However, despite examples of excellent practice and enthusiastic recommendations from clients, access and referral processes were areas of weakness.

\section{Conclusion}

In England, local authorities have an important role to play in tackling obesity. It is crucial that they are provided with the tools to be able to implement healthy weight interventions effectively. A whole-systems approach presents a real opportunity for staff in local authorities and public health to work collaboratively and innovatively towards the same goal of continuous improvement in obesity management.

Keywords: evaluation; obesity; weight management; interventions; local authority, wholesystem approach.

\section{Corresponding author:}

Nicky, H. Kime, Carnegie School of Sport, Fairfax Hall, Headingley Campus, Leeds Beckett University, Leeds, LS6 3QT, UK.

Email: N.Kime@leedsbeckett.ac.uk 


\section{Background}

Obesity is a national and international priority with an increasing proportion of people who are overweight or obese ( $\mathrm{Ng}$ et al, 2014). More than 4.5 million children and 30.8 million adults in the UK are either overweight or obese (Health Survey for England, 2012; Office of National Statistics, 2012). Globally, over 650 million people are obese, which represents approximately $13 \%$ of the world's adult population (WHO, 2017a).

Obesity is an established risk factor for many diseases, most notably cardiovascular diseases, type 2 diabetes and many types of cancer. It is responsible for at least 2.8 million adult deaths globally each year (Department of Health, 2008a, 2010 and 2011; National Audit Office and Healthcare Commission, 2006; NHS Information Centre, 2011; Swinburn et al, 2011; WHO, 2017b). This translates into an enormous economic burden with current estimates suggesting that the international impact from obesity is roughly $\$ 2.0$ trillion annually (Dobbs et al, 2014). In the UK, the costs to the NHS of the health effects from obesity are approximately $f 6.1$ billion per year, but the wider social costs amount to $£ 27$ billion (Department of Health, 2008b). Of further concern is that if no action is taken, it is estimated that by 2050 , obesity-related diseases could cost the UK as much as $£ 45.5$ billion per year (King, 2011).

Given this evidence, public health strategies to combat the rising incidence of obesity require implementation and evaluation. An integrated, whole-systems approach has been widely advocated for, based on a broad ecological model that considers both individual and population level, or environmental, determinants of obesity (Foresight, 2007; Cohen et al, 2000). In line with a whole-systems approach, current obesity guidance recommends that multiple sectors are involved at all societal and policy levels, including health, social care, planning, transport, housing and business. This means that co-ordinated and collaborative action is necessary to understand and act upon the many facets of the environment, including physical, dietary, social, economic and cultural aspects, as well as behaviour change components (Dobbs et al, 2014; Foresight, 2007; Leeds Beckett University, 2017; National Audit Office, 2012; NICE, 2017; Stegenga et al, 2014).

In recent years the public health system in England has undergone unparalleled change, which has meant that the ownership and responsibility for tackling obesity has not always been apparent. In April 2013, the management of obesity (excluding medical management) was transferred from Primary Care Trusts (PCTs) to Clinical Commissioning Groups (CCGs) and Health and Wellbeing Boards (HWBs). PCTs were administrative organisations forming part of the National Health Service in England from 2001 to 2013 and were largely responsible for commissioning health services from providers. CCGs and HWBs effectively replaced PCTs and were created as a result of the Health and Social Care Act in 2012 (Campbell, 2012). CCGs are clinically-led statutory bodies that commission the majority of health care services for patients within a local area. HWBs are part of local authorities (the lowest tier of government) and are responsible for promoting greater integration between health services, public health and local government. They work in partnership with CCGs to improve the health and wellbeing of the local population through the creation of a joint health and wellbeing strategy. This strategy includes the delivery of healthy weight services. At the same time as CCGs and HWBs were introduced, information on tackling obesity was, and continues to be, typically generic, in 
character, providing general rather than specific guidance. Consequently, there have been few clear directives at a local level on how to establish, deliver and evaluate healthy weight services.

Evaluation is key to understanding which aspects of public health interventions are more successful than others. However, the focus is often on a single population group, for example, children or families (Jinks et al, 2013; Visram et al, 2013). In contrast, this study sought to gain a greater appreciation of the many interacting components across a wider range of healthy weight interventions involving multiple groups and different populations.

This paper focuses on one local authority (which we name 'LA- $Y$ '), where obesity levels have remained above the national average since 2006. Worryingly, current levels of obesity in LA-Y are higher than the public health England benchmark of $26 \%$ men and $23.8 \%$ women (Public Health England, 2015). This is despite the statutory responsibility of local authorities to deliver the National Child Measurement Programme (NCMP) as one of its mandatory public health duties. The key purpose of this is to provide robust public health data on the status of children's weight and better understand obesity prevalence (Public Health England, 2013). In response to its rising obesity problem, LA-Y implemented a healthy weight strategy in 2010 . The primary objective was to improve the health of the local population, including children, through the identification and implementation of effective strategies to prevent and treat obesity.

LA-Y commissioned an evaluation of its healthy weight related services in 2013 . The timeframe for the evaluation was 6 -months, a requirement imposed by local authority commissioners. For the purposes of the evaluation they distinguished between prevention and treatment, commissioning Leeds Beckett University to evaluate the treatment provision. So far as the aims of the evaluation were concerned, LA-Y wished to ascertain how well:

- healthy weight services provided a sufficiently comprehensive range to ensure appropriate access;

- pathways into and between the different services were clearly established; and

- services were delivering the desired outcomes in terms of the achievement of healthy weight.

Here we report on the qualitative evaluation of the treatment provision within LA-Y's healthy weight strategy.

\section{Methods}

\section{Evaluation approach}

The Standard Evaluation Framework (SEF) for weight loss interventions originally suggested by the UK National Obesity Observatory was used as a guide and this informed the collection of appropriate information, but only where information in each service was available (Roberts et al, 2009).

Given the short time frame for the evaluation, it was not possible to evaluate all the services that formed part of LA-Ys healthy weight strategy. Therefore, six services (from more than 20) that directly delivered activity to improve healthy eating, reduce obesity and increase levels of physical activity were selected by LA-Y to participate in the evaluation; Leeds Beckett University 
had no involvement in the selection of these services. It was a requirement of the evaluation that details of the local authority are not provided and, therefore, the location and names of the services are anonymised. See Table 1 for an overview of services that participated.

The evaluation included both process and outcome evaluation. The former concerned the delivery of services from the perspectives of the participants in the qualitative evaluation. The latter assessed the effectiveness of the different services in terms of the achievement of healthy weight.

\section{Data collection}

A qualitative methodology was adopted and this paper reports on the findings from that evaluation. Qualitative data was collected between July and December 2013 in order to explore in more detail how well the healthy weight services were working from the perspective of the participants. Focus group discussions and semi-structured interviews were used to allow participants relatively free scope to explore and elaborate on their own views and experiences (Mansell et al, 2004).

Practitioners, healthcare professionals, clients and volunteers from each of the services were recruited. The practitioners were those working in the community, for example, activity leaders, who were responsible for service delivery, assisted by volunteers. Healthcare professionals comprised those working in primary or secondary care, for example, consultants and dietitians. None of the participants had any contact with, or were known to, the research team prior to the evaluation. In all cases, purposive sampling was adopted to bring together individuals who satisfied the inclusion criteria established by LA-Y: women and men of any age and ethnicity and actively engaged in one of the services, either as a member of staff, a volunteer or client. Practitioners and healthcare professionals were contacted directly by email or telephone by the research team on instruction from LA-Y and clients and volunteers were informed about the evaluation via the practitioners and healthcare professionals working in the healthy weight services. Potential participants who requested further details were sent an information sheet and a consent form. When the signed consent form was returned participants were invited to attend a focus group discussion or a one-to-one interview. Focus groups were held at a venue in the local community and arranged at a time to suit the participants. Interviews were conducted face-to-face or by telephone.

A separate focus group and interview schedule was developed for clients and staff to guide the questions (see online supplementary material). These were piloted beforehand to check the language used, participants' understanding and the suitability of the questions in relation to the evaluation aims. They were also adapted with each subsequent focus group or interview according to key issues that emerged. Focus groups and interviews were conducted until data saturation was achieved and none were repeated. All the focus groups followed best practice guidelines, which meant the lead author (female) facilitated the discussion and a second researcher (male) made notes to capture paralanguage, contextual meanings, and so on (Kruger and Casey, 2008). Both authors are qualified researchers and experienced in conducting qualitative evaluations using focus groups or interviews. The lead author introduced the research team and outlined the reasons for the evaluation prior to the commencement of the focus group or interview. Each focus group lasted approximately 1 hour 30 minutes and included between 4 and 8 people and the interviews lasted between 30 minutes to 1 hour. Focus groups and 
interviews were recorded with the participants' written and verbal consent and all took part voluntarily; no participation incentives were offered. Ethical approval was obtained from Leeds Beckett University and the Research and Development department in LA-Y. The evaluation followed COREQ (consolidated criteria for reporting qualitative research) guidelines (Tong et al, 2007). See the online supplementary material for the COREQ checklist.

\section{Analysis}

Qualitative data from the focus group discussions and interviews was recorded, transcribed and analysed using a thematic analysis approach (Attride-Stirling, 2001). Analysis and interpretation followed a framework approach, which is a practical and effective way of managing, summarising and synthesising complex qualitative data (Ritchie and Lewis, 2003). The analytic process was both deductive and inductive in character. A deductive approach guided by the process and outcome strands of the evaluation, alongside an inductive approach that was data driven. Together these involved generating categories and coding data so that common links and themes could be identified. No software was used in the analysis, instead two, and occasionally three, researchers were involved in the coding process, thereby reducing interpretation bias. In addition, research participants verified the themes as a means of establishing the reliability of the research findings.

\section{Results}

Overall, 91 participants took part in the evaluation. A total of 7 focus groups, all involving adults, and 33 semi-structured interviews, 7 with children and 30 with adults, were conducted. All those participants that consented to participate in a focus group or interview attended.

See Table 2 for a breakdown of the participants who took part in the evaluation. Participants' characteristics have not been identified because of the small number of individuals representing each of the services and the risk of compromising anonymity.

The findings are structured according to the framework of Attride-Stirling (Attride-Stirling, 2001). A global theme together with an explanation of the organising themes that led to its development are presented. See Table 3 for a full breakdown of the global, organising and basic themes.

\section{Process evaluation}

The findings revealed two global themes: staff competencies and access

\section{Staff competencies}

Personality. A unique selling point of the different services was the competencies of the staff, who included practitioners, healthcare professionals and volunteers. Those clients who participated in the evaluation commented on the positive personalities that they encountered and stated that the staff were largely enthusiastic, supportive and passionate about what they did. This was endorsed by consistently positive feedback from clients: 
It's the positive environment that makes people believe they can do it; fantastic tutors that make it fun...staff are inspiring" (Client; Service 1)

Knowledge. Clients reported that staff seemed knowledgeable in relation to health education and behaviour and, most importantly, they were able to provide appropriate information that they had not necessarily received from their local doctor. Information was normally in the form of practical strategies for healthy eating and increasing physical activity, which people could take away and have a go at implementing:

Amazing place, amazing people, it's great, it really is. They just answer your questions just like that. Here I know, any information I wanna know is provided (Client; Service 3)

She weighed me and we had some ideas that l'd try...she's given me some good ideas...I think we'll get there (Client; Service 3)

Training. Many staff were trained in motivational interviewing and behaviour change theory. This meant they favoured a client-centred, solution-focused approach, with the emphasis on overall health status rather than just weight loss. Clients felt that this approach was more supportive and encouraged them to attend the service, knowing that they were not going to be reprimanded if they failed to achieve their goals:

It's not all, 'don't do this, don't do that', I look forward to coming here (Client; Service 3)

Staff reported that an important factor in the drive to combat weight gain was consistency in respect of training, where it was imperative that all staff were trained in the same key principles and relayed the same messages. One member of staff stated:

Everyone needs to sing from the same hymn sheet (Staff; Service 1)

Staff reported that there needed to be greater training opportunities in order to raise awareness of the different services and the individual roles of staff within these services. Staff felt that they were not always viewed by others outside of their service as professionals in their own right and, therefore, their role lacked credibility amongst other organisations.

Sometimes I feel that...'well you guys can deal with it. I don't really know what you do, but you can deal with it'. Sometimes that's the attitude. They don't think that we're professional in that sense (Staff; Service 2)

\section{Access}

Barriers. Practitioners, healthcare professionals, volunteers and clients all recognised that access to the different healthy weight services depended on an individual's ability to overcome barriers and the appropriate referral routes being in place. Although staff made an effort to engage populations that were considered "hard to reach", for example, men and BME communities, they acknowledged that participation in the different services was most difficult for those living in the more economically and socially deprived areas or who were less mobile. Difficulties were linked 
to language, childcare, budget, the location of the service, transport and availability of specialised resources.

It's not always easy for people to get here, for example, older people who cannot walk and we do not have insurance to go and collect them (Staff; Service 5)

One of the main barriers preventing clients from accessing continued support was that some staff did not have the capacity to see clients sufficiently often over a sustained period. This was due to the increasing number of clients and fewer client contact hours that staff had available. Therefore, it was unsurprising that clients reported they had to wait too long in between sessions:

I don't know why it was so long before I heard anything. I can't really complain, it's a free service. My only concern is how long it takes to get in to next consultation. I appreciate it's a long process and lots of people to be seen (Client; Service 3)

Many clients reported that they needed to attend a service on a regular basis, in order to remain motivated to lose weight:

(It's) helped by having access to someone saying, 'you're doing well'. Doesn't matter if you have a lapse, can still carry on... a routine helps and having someone there to give you a push (Client; Service 2 )

Referrals. Pathways for referring clients into individual services were largely well established with the majority of clients reporting that the referral process was very efficient in their experience:

I got referred on the Monday, on Tuesday the referral letter arrived and Wednesday I attended the session (Client; Service 4)

However, initial information about the availability of different services in the locality was difficult to come by and many clients reported that they had little, if any, awareness of the opportunities open to them:

I don't know that it's well documented, I didn't even know that it existed. I spoke to my GP. I went in a moment of desperation and she referred me here (Client; Service 3)

There was an absence of clear and robust referral routes between the different services and no obvious process for establishing these, which created confusion amongst staff and clients. Consequently, referrals between primary and secondary care and community services occurred on an infrequent and random basis. Staff were frustrated that few formal partnerships were in place between individual services as a result of inadequate referral routes. Those partnerships that did exist were largely informal with no recognised agreements in place, despite many staff acknowledging that good working relationships and efficient referral systems were central components to the effectiveness of any healthy weight strategy.

The timing between the referral and delivery is crucial to a successful healthy lifestyle change... it is vital to strike while the iron is hot (Staff; Service 3) 


\section{Outcome evaluation}

Analysis of the outcome data revealed two further themes: empowerment and weight loss.

\section{Empowerment}

Holistic Health. For many clients, the emphasis given to holistic health, including mental health, was an important factor in their continued engagement with a service.

Staff and clients stated that it was the focus on wellness and an individual's overall attitude to health and wellbeing that tended to characterise service delivery rather than an emphasis on illness or any one particular aspect of health, for example, weight loss. This type of approach, together with the enthusiasm of staff, meant that clients felt empowered to take responsibility for their overall health rather than simply focusing on weight:

It's really changed my life, 'cos they're really brilliant...anything you want they can do, it teaches you to do everything...feel so much better than I used to (Client; Service 1)

Many clients reported having a close working relationships with staff and felt they were appropriately involved in decision-making. They appreciated that they were consulted rather than ignored and as a consequence, benefited from enhanced self-esteem. They felt empowered to take a more positive approach to their overall health and were motivated to become healthier:

They (staff) ask you what you want to do and expose you to different ideas...you think, 'I can do it, I can do it' and it really improves your health (Client; Service 2)

Clients consistently emphasised the different services' suitability for all, regardless of an individual's health or weight status. They appreciated that staff were non-judgemental and services were not prescriptive, but rather tailored to the individual and their needs. Most staff and clients recognised the wider benefits of the different healthy weight services in terms of social support. However, while clients valued the sociability aspect of group sessions, the majority gained the most benefit from individual consultations.

Much more tailored around me. Does feel more personable, centered on you. Get the uplift that may be it will work this time...don't get the same sort of feeling from group sessions (Client; Service 3).

A minority of clients valued the availability of one-to-one and group sessions since this allowed them greater freedom to utilise different approaches at different times.

\section{Weight loss}

Lifestyle. As a result of attending a healthy weight service, clients reported a more positive approach to health behaviour and a change from a sedentary to a physically active lifestyle, which resulted in them losing weight. In many cases, this initial weight loss not only incentivised clients 
to lose more weight, but renewed self-confidence to try other healthy weight services, which further increased weight loss:

I lost 25lb (previously). Have just moved to BABH, been there for 2 weeks and I've lost 3.5lb (Client; Service 1)

Although their original reason for attending a service was to lose weight, many clients acknowledged that they had gained a greater understanding of the importance of lifestyle and its influence on their weight status:

With diets a lot of it, it's down to me. I'm starting to get my head round that it's my lifestyle not just diet (Client; Service 3)

\section{Discussion}

This evaluation involved a qualitative appraisal of an English local authority's healthy weight strategy. It has shown that in trying to deliver on its strategic aims, the local authority set up a range of healthy weight services which were, in part, meeting the needs of its population.

In respect of LA-YS service provision, staff were highly motivated and worked hard to accommodate the varying needs of a diverse population. Processes were in place to ensure that services were client-centred and organised to optimise accessibility and attendance as much as possible.

In terms of desired outcomes around healthy weight, it was less clear how well LA-Y was performing, although qualitative evidence suggested that the different healthy weight services in LA-Y were largely engaging and beneficial for clients, particularly in respect of empowerment and holistic health.

Major areas of weakness for LA-Y lay in partnership working and referral pathways between the different services. These were largely inadequate which meant that clients often missed out on the most appropriate treatment, negatively impacting on long-term health outcomes.

Furthermore, once clients were enrolled in a service there was often a long wait between sessions and, therefore, it was hard for them to remain motivated.

Public Health England has reported on the difficulties faced by many local authorities in tackling obesity, many of which apply to LA-Y and its healthy weight strategy (Public Health England, 2014). These include a lack of expertise in setting up and delivering a strategy that is able to balance an array of prevention and treatment services across a large and diverse population. Due to the complexity of obesity management, there is also a lack of joined-up working between single interventions, and therefore, effective population-level outcomes are unlikely to be realised (Office of Health Economics, 2010; NICE, 2013 and 2014; Public Health England, 2014). In contrast, multiple interventions which are part of an integrated whole-system approach in which services are tailored to service users' individual needs, will likely have the a more sustainable impact (Foresight, 2007; Local Government Association, 2013; Royal College of Physicians, 2013). 


\section{Limitations}

This evaluation focused only on one local authority and its findings cannot be generalised beyond this context. Nevertheless, the salient themes highlighted in this study relate to a national health priority area, obesity, and may likely be pertinent to local authorities and public health teams elsewhere.

In respect of qualitative data, relying on volunteers always risks favouring the subjective contributions of the most motivated and vocal participants. Staff may be eager to present their service in the best possible way to safeguard the service and their job and likewise, clients may be equally positive, in order to ensure continued treatment provision.

\section{Conclusion}

Given recent changes in public health in England, there can be little doubt that the decision to commission an evaluation of LA-Y's healthy weight strategy was a bold move. LA-Y officials chose to place their authority's work in the spotlight and our evaluation highlighted strengths as well as weaknesses in healthy weight provision.

Local authorities continue to have an important role to play in addressing obesity and it is crucial that they are provided with the resources and tools to be able to implement healthy weight interventions effectively. Central support from Public Health England (PHE) is a key contributory factor in this respect. Based on the evaluation findings presented here, PHE should consider providing guidance on implementing healthy weight services that are appropriately tailored to clients' individual needs, are inter-connected by recognised referral routes and which demonstrate effective partnership working. Looking ahead, support may soon be forthcoming following Public Health England's collaborative work to tackle obesity, which is focused on the development of a whole-systems approach (WSA) that is applicable at a local authority level (Leeds Beckett University, 2017). Support in the form of a practical guide to help local authorities create a WSA in their local area is currently being developed. This 'route map' will offer guidance on how to set up a WSA, alongside supporting information and tools to facilitate the process (Local Government Association, 2017). Targeting a single cause of obesity is unlikely to be effective. Rather, a coordinated WSA approach that includes PHE, local authorities and an extensive range of stakeholders, offers the opportunity for all parties to work collaboratively and innovatively towards the same goal of continuous improvement in obesity management.

\section{Acknowledgements}

We thank the clients, volunteers, practitioners and healthcare professionals who gave their time to participate in this evaluation.

\section{Funding}

This work was supported by LA-Y Public Health.

\section{Declaration of conflicting interests}

The authors declare that they have no conflicting interests. 


\section{References}

Attride-Stirling J (2001) Thematic networks: an analytical tool for qualitative research. Qualitative Research, 1: 385-405.

Campbell, F (2012) Get in on the Act. Health and Social Care Act 2012.London: Local Government Association.

Cohen DA, Scribner MD and Farley MD (2000) A structural model of health behaviour: A pragmatic approach to explain and influence health behaviors at the population level. Preventive Medicine, 30: 146-154.

Department of Health (2008a) Help stop childhood obesity before it starts. London: HMSO.

Department of Health (2008b) Healthy Weight, Healthy Lives: A toolkit for developing local strategies. London: HMSO.

Department of Health (2010) Childhood Obesity National Support Team. Update of Findings. London: HMSO.

Department of Health (2011) Healthy Lives, Healthy People: A Call to Action on Obesity in England. London: HMSO.

Dobbs R, Sawers C, Thompson F (2014) Overcoming obesity: An initial economic analysis. London: McKinsey Global Institute.

Foresight (2007) Tackling obesities: Future Choices Report. London: HMSO.

Health Survey for England (2012) Health, social care and lifestyles. Available from: http://www.hscic.gov.uk/catalogue/PUB09300 (accessed 03 February 2017).

Jinks A, English S and Coufopoulos A (2013) Evaluation of a family-centred children's weight management intervention. Health Education, 113(2): 88-101.

King, D (2011) The future challenge of obesity. Lancet, 378: 743-744.

Kruger RA and Casey MA. (2008) Focus groups: a practical guide for applied research. London: Sage.

Leeds Beckett University (2017) A Whole Systems Approach. Available from: http://www.leedsbeckett.ac.uk/wholesystemsobesity/a-whole-systems-approach (accessed 15 October, 2017).

Local Government Association (2013) Tackling obesity: Local government's new public health role. London: LGA.18.

Local Government Association (2017) Making obesity everybody's business: A whole systems approach to obesity. London: LGA. 15.6.

Mansell I, Bennett G, Northway R, et al. (2004) The learning curve: the advantages and disadvantages in the use of focus groups as a method of data collection. Nurse Researcher 11(4): 79-88.

National Audit Office and Health Care Commission (2006) Tackling Obesity - First Steps. London: HMSO.

National Audit Office (2012) An update on the government's approach to tackling obesity. London: NAO.

$\mathrm{Ng}, \mathrm{M}$ et al. (2014) Global, regional, and national prevalence of overweight and obesity in children and adults during 1980-2013: a systematic analysis for the Global Burden of Disease Study 2013. Lancet, 384: August 30, 2014.

NHS Information Centre (2011) Health Survey of England. Statistics on obesity, physical activity and diet. London: HMSO.

NICE (2013). Managing overweight and obesity among children and young people: lifestyle weight management services. London: NICE. 
NICE (2014) Weight Management: Lifestyle Services for Overweight or Obese Adults. Available at: https://www.nice.org.uk/guidance/ph53 (accessed 28 June 2018)

NICE (2017) Obesity prevention. Clinical guideline CG43. Available from: https://www.nice.org.uk/guidance/cg43 (accessed 14 October, 2017).

Office of Health Economics (2010) Shedding the pounds. Obesity management, NICE guidance and bariatric surgery in England. London: Office of Health Economics.

Office of National Statistics (2012) Population estimates for 2012. Available from: http://www.ons.gov.uk/ons/dcp171778_320900.pdf (accessed 03 February 2017).

Public Health England (2013) National Child Measurement Programme: Briefing for elected members. London: PHE.

Public Health England (2014) Public Health England and Association of Directors of Public Health survey findings: Tackling Obesity. London: PHE.

Public Health England (PHE) (2015) Statistics on Obesity, Physical Activity and Diet - England. Available at:

http://webarchive.nationalarchives.gov.uk/20180328133908/http://digital.nhs.uk/catalog ue/PUB23742 (accessed 28 June 2018).

Ritchie J and Lewis J (2003) Qualitative Research Practice: A Guide for Social Science Students and Researchers. London: Sage.

Roberts K, Cavill N, Rutter H (National Obesity Observatory) (2009) Standard Evaluation Framework for weight management interventions. London: National Obesity Observatory.

Royal College of Physicians (2013) Action on obesity: comprehensive care for all. Report of a working party. London: RCP.

Stegenga H, Haines A, Jones K, Wilding J. (2014) Identification, assessment, and management of overweight and obesity: summary of updated NICE guidance. BMJ, 349: g6608.

Swinburn BA, Sacks G, Hall K, McPherson K, Finegood D, Moodie M, Gortmaker S (2011) The global obesity pandemic: shaped by global drivers and local environments. Lancet, 378 : 804-814.

Tong A, Sainsbury P and Craig J (2007) Consolidated criteria for reporting qualitative research (COREQ): a 32-item checklist for interviews and focus groups. International Journal of Qualitative Health Care, 19(6): 349-357.

Visram S, Hall TD, Geddes L (2013) Getting the balance right: qualitative evaluation of holistic weight management intervention to address childhood obesity. Journal of Public Health, 35(2): 246-254.

World Health Organization (WHO) (2017a) 10 Facts on Obesity. Available from: http://www.who.int/features/factfiles/obesity/en (accessed 14 October 2107).

World Health Organization (WHO) (2017b) Factsheet on Overweight and Obesity. Available from: http://www.who.int/mediacentre/factsheets/fs311/en (accessed 9 October 2017). 
Table 1: Services participating in the evaluation

\begin{tabular}{|c|c|c|c|c|c|c|}
\hline & \multicolumn{6}{|c|}{ Healthy Weight Services } \\
\hline & Service 1 & Service 2 & Service 3 & Service 4 & Service 5 & Service 6 \\
\hline $\begin{array}{l}\text { Service } \\
\text { Description }\end{array}$ & $\begin{array}{l}\text { Age- } \\
\text { appropriate } \\
\text { programmes to } \\
\text { improve } \\
\text { physical activity } \\
\text { levels \& overall } \\
\text { health. }\end{array}$ & $\begin{array}{l}\text { General lifestyle } \\
\text { advice \& support } \\
\text { to improve } \\
\text { healthy living. } \\
\text { Includes C, an } \\
\text { evidence-based } \\
\text { weight } \\
\text { management } \\
\text { approach. }\end{array}$ & $\begin{array}{l}\text { Assesses and } \\
\text { treats } \\
\text { overweight/ } \\
\text { obese adults } \\
\text { and children. } \\
\text { Combined with } \\
\text { physical activity } \\
\text { provision in the } \\
\text { community. } \\
\text { Adult bariatric } \\
\text { provision. }\end{array}$ & $\begin{array}{l}\text { GP referral to a } \\
\text { weight } \\
\text { management } \\
\text { programme. } \\
\text { Delivered by } \\
\text { Slimming World. }\end{array}$ & $\begin{array}{l}\text { Development of } \\
\text { local cooking clubs } \\
\text { and support for } \\
\text { meal preparation. }\end{array}$ & $\begin{array}{l}\text { National statutory } \\
\text { scheme that weighs and } \\
\text { measures children in } \\
\text { primary schools. }\end{array}$ \\
\hline Service Length & $\begin{array}{l}\text { Depends on the } \\
\text { individual } \\
\text { programme, } \\
\text { e.g. } 12 \text { weeks. }\end{array}$ & $\begin{array}{l}12 \text { weeks - once } \\
\text { a week for } 4 \\
\text { weeks and then } \\
\text { every } 2 \text { weeks. }\end{array}$ & $\begin{array}{l}\text { Paediatrics - } 4 \\
\text { appointments } \\
\text { approx. every } 3 \\
\text { months over a } \\
\text { 12-month } \\
\text { period. } \\
\text { Adults - at least } \\
12 \text { months. } \\
\text { Frequency of } \\
\text { appointments } \\
\text { varies. }\end{array}$ & $\begin{array}{l}12 \text { weeks - } \\
\text { attendance at } \\
\text { classes once a } \\
\text { week. }\end{array}$ & $\begin{array}{l}\text { 9-week healthy } \\
\text { cooking courses or } \\
\text { regular cooking } \\
\text { taster sessions. }\end{array}$ & $\begin{array}{l}\text { Data collected in } \\
\text { reception and year } 6 .\end{array}$ \\
\hline $\begin{array}{l}\text { Inclusion Criteria } \\
\text { and Referral }\end{array}$ & $\begin{array}{l}\text { Aged } 2-80+\text {. For } \\
\text { certain } \\
\text { programmes } \\
\text { individuals } \\
\text { need to be } \\
\end{array}$ & $\begin{array}{l}\text { Anyone aged } 18+ \\
\text { and } \mathrm{BMI}>25 \text { or } \\
>23 \text { with health } \\
\text { related issues. } \\
\text { Referral by }\end{array}$ & $\begin{array}{l}\text { Children - high } \\
\text { BMI/centile (no } \\
\text { defined figure). } \\
\text { Adults - } \\
\text { morbidly obese } \\
\end{array}$ & $\begin{array}{l}\text { Anyone aged } \\
18+. \text { Referral by } \\
\text { GP. }\end{array}$ & $\begin{array}{l}\text { Anyone aged 18+. } \\
\text { Self-referral. }\end{array}$ & $\begin{array}{l}\text { All children in reception } \\
\text { and year } 6 . \\
\text { Referral through school. }\end{array}$ \\
\hline
\end{tabular}




\begin{tabular}{|l|l|l|l|l|l|}
\hline & $\begin{array}{l}\text { overweight or } \\
\text { obese. } \text { Referral } \\
\text { by health } \\
\text { professional or } \\
\text { self-referral. }\end{array}$ & $\begin{array}{l}\text { health } \\
\text { professional or } \\
\text { self-referral. }\end{array}$ & $\begin{array}{l}\text { (BMI 40+) } \\
\text { although other } \\
\text { co-morbidities } \\
\text { considered. } \\
\text { Referral by GP. }\end{array}$ & & \\
\hline
\end{tabular}


Table 2: Participants in the evaluation

\begin{tabular}{|c|c|c|c|c|c|c|}
\hline \multirow{3}{*}{$\begin{array}{c}\text { Type of } \\
\text { Participants }\end{array}$} & \multicolumn{6}{|c|}{ Healthy Weight Services } \\
\hline & Service 1 & Service 2 & Service 3 & Service 4 & Service 5 & Service 6 \\
\hline & \multicolumn{6}{|c|}{ Number of Participants } \\
\hline Practitioners & 13 & 7 & & 2 & 5 & 6 \\
\hline Healthcare Professionals & & & 9 & & & \\
\hline Clients & 16 & 2 & 8 & 9 & 2 & 4 \\
\hline Volunteers & 8 & & & & & \\
\hline Total & 37 & 9 & 17 & 11 & 7 & 10 \\
\hline Overall Total & \multicolumn{6}{|c|}{91} \\
\hline
\end{tabular}


Table 3: Thematic analysis

\begin{tabular}{|c|c|c|}
\hline Basic themes & Organising themes & Global themes \\
\hline Committed & \multirow{4}{*}{ Personality } & \multirow{12}{*}{ Staff competencies } \\
\hline Positive & & \\
\hline Personable & & \\
\hline Supportive & & \\
\hline Skilled & \multirow{4}{*}{ Training } & \\
\hline Client-centred & & \\
\hline Solution-focused & & \\
\hline Professionalism & & \\
\hline Education & \multirow{4}{*}{ Knowledge } & \\
\hline Physical Activity & & \\
\hline Diet & & \\
\hline Behaviour change & & \\
\hline Hard to reach & \multirow{11}{*}{ Barriers } & \multirow{17}{*}{ Access } \\
\hline Language & & \\
\hline Costs & & \\
\hline Socio-economic status & & \\
\hline Time & & \\
\hline Location & & \\
\hline Funding & & \\
\hline Childcare & & \\
\hline Duration & & \\
\hline Intermittent & & \\
\hline Staff resource & & \\
\hline Partnership working & \multirow{6}{*}{ Referrals } & \\
\hline Connectivity & & \\
\hline Sustainability & & \\
\hline Advertising & & \\
\hline Publicity & & \\
\hline Promotion & & \\
\hline Physical & & \\
\hline
\end{tabular}




\begin{tabular}{|c|c|c|}
\hline Mental & \multirow{5}{*}{ Holistic Health } & \multirow{5}{*}{ Empowerment } \\
\hline Groups & & \\
\hline Family & & \\
\hline Sociability & & \\
\hline Decision-making & & \\
\hline Sedentary & \multirow{3}{*}{ Lifestyle } & \multirow{3}{*}{ Weight loss } \\
\hline Active & & \\
\hline Diet & & \\
\hline
\end{tabular}

